\title{
Electrical and thermal effects of fault currents in aircraft electrical power systems with composite aero-structures.
}

\author{
Catherine E. Jones, Patrick J. Norman, Michal Sztykiel, Rafael Peña Alzola, Graeme M. Burt \\ Member, IEEE, Stuart J. Galloway, Luiz F. Kawashita, Stephen R. Hallett
}

\begin{abstract}
The upwards trend for the use of electrical power on state of the art aircraft is resulting in significant change to the design of power system architectures and protection systems for these platforms. There is a pull from the aerospace industry to integrate the electrical power system with the aircraft's structural materials to form an embedded system, reducing the need for bulky cable harnesses. This directly impacts the fault response for ground faults and ultimately the development of appropriate protection systems. Such structural materials include composites such as carbon fibre reinforced polymer (CFRP). This paper presents the experimental capture and analysis of the response of CFRP to electrical fault current, which indicates the need for two distinct sets of electrical ground fault detection criteria for low and high resistance faults and identifies the threshold resistance for this distinction. By extrapolating these results to develop models of CFRP for use in transient simulation studies, the key electrical fault detection thresholds for speed, selectivity and sensitivity for a DC system rail to ground fault through CFRP are identified. This provides the first set of key factors for electrical fault detection through CFRP, providing a platform for the design of fully integrated structural and electrical power systems, with appropriate electrical protection systems.
\end{abstract}

Index Terms- Carbon fibre reinforced polymer, electrical protection, more-electric aircraft.

\section{I.INTRODUCTION}

Ninc TATE of the art more-electric aircraft (MEA) utilise increased numbers of electrical, rather than pneumatic or hydraulic, loads to attain improved engine efficiency which results in reduced fuel burn and hence lower emissions [1]. Coupled with this there is an upwards trend for the use of carbon fibre reinforced polymer (CFRP) structural materials due to their superior mechanical characteristics compared to traditional metallic materials [2]. Combined, these two elements of modern aircraft design are key enablers to meet future performance targets, whilst satisfying the increasing demand for air travel [3].

Increasing the installed electrical power and use of composite materials continue to have a significant impact on the design of the electrical power system of MEA and future aircraft. The increase in on-board electrical power generation has resulted in significant changes to electrical power system architectures to ensure efficiency benefits of electrical loads are not mitigated, including higher voltage levels to enable more distributed architectures, variable frequency AC and more extensive use of DC sections of network [2][4][5]. Critical to the operation of this aero-electrical power system, is an application-appropriate electrical protection system, which must reliably detect and appropriately respond to faults, such that (in the worst case scenario) an aircraft is able to land safely after an electrical fault has occurred. The first step to design a fully optimised electrical protection system, is the capture of electrical fault detection criteria.

Currently, heavily insulated cables are bundled in harnesses on aircraft, resulting in bulky structures which are difficult to manipulate and susceptible to damage both during maintenance and from vibration during flight operations [6]. Integration of the electrical power system with composite structural materials has been proposed as a solution to significantly reduce the need for routing power cables in harnesses [6]. Hence, an informed understanding of the of the fault response for a rail to ground fault through CFRP, and consequential appropriate methods of fault detection, supporting the future development of appropriate electrical protection solutions, to reduce the use of harnesses and enable integration of the electrical power system with the CFRP.

Of particular interest is that, if a rail to ground fault occurs, the fault current may travel through a section of CFRP in order to reach the current return network because it is known that the electrical conductivity of CFRP is much poorer than a metallic structure, impacting on ground fault response [7]. The laminate stacking sequence and method of electrically bonding it to electrical ground are both expected to influence the electrical resistance added to a ground fault path by CFRP, and the electrical fault detection requirements. The capture of these fault detection criteria is needed to enable the optimised selection and design of future protection and fault management systems for integrated electrical power system and composite structures. These aspects are interdependent with the structure and design of the on-board electrical power system.
Paper submitted for review on $11^{\text {th }}$ December 2017. This work was supported by Rolls-Royce plc through the Advanced Electrical Power Systems University Technology Centre (UTC) at the University of Strathclyde, and the Composites UTC at the University of Bristol.

C.E. Jones (catherine.e.jones@strath.ac.uk), P.J. Norman (patrick.norman@srath.ac.uk), M. Sztykiel (michal.sztykiel@strath.ac.uk), R.
Peña-Alzola (rafael.pena-alzola@strath.ac.uk), S.J. Galloway (stuart.galloway@strath.ac.uk) and G.M. Burt (graeme.burt@strath.ac.uk) are with the University of Strathclyde, 16 Richmond Street, Glasgow, U.K., G1 1XQ. L.F. Kawashita (luiz.kawashita@bristol.ac.uk) and S.R. Hallett (stephen.hallett@bristol.ac.uk) are with the Bristol Composites Institute, University of Bristol, University Walk, Bristol, U.K., BS8 1TR. 
This is a pre-print of TTE-Reg-2017-12-0232, accepted by the IEEE Trans. on Transportation Electrification on $19^{\text {th }}$ April 2018 and as such is subject to IEEE copyright.

Whilst it is well understood in the literature that a lightning strike on CFRP will result in acoustic shock and rapid Joule heating [8][9] lightning strike is very different to a sustained electrical fault current. It is an impulse of high power delivered over a short period $(<0.1 \mathrm{~ms})$ of time, rather than a lower power delivered over a period of seconds, as is expected for a high impedance electrical ground fault.

This paper addresses the need to understand how CFRP responds to electrical fault current, both electrically and thermally, and from this identifies and assesses the new fault detection criteria, which will influence future protection systems design allowing the efficient integration of aeroelectrical systems with composite structures. This paper will first present the current trends for composite MEA, including architectures and grounding. Secondly the key protection considerations for a fault to ground through CFRP are identified. Thirdly the experimental capture of the response of CFRP is presented and results are extrapolated to higher power levels and different CFRP layups, to determine new fault detection criteria for faults to ground through CFRP materials (in particular speed and sensitivity).

\section{II.INTEGRATION OF COMPOSITE AERO-STRUCTURES WITH MEA POWER SYSTEMS}

\section{A. State of the Art Grounding in Composite Airframes}

An integrated approach to the design of the structure of an aircraft and the electrical power system has historically been taken, with the traditional metallic aircraft structure forming a current return network, due to its low electrical impedance (resulting in a minimal voltage drop over the current return path) [10]. Hence, the much lower electrical conductivity of CFRP compared to aluminium has had a significant impact on the design and optimisation of the current return path of stateof-the-art aircraft [11].

On a composite aircraft, where CFRP has a relatively high impedance compared to aluminium, an alternative method to using the aircraft skin for current return has been developed [12][13]. In this method a current return network (CRN) [12] or electrical structural network (ESN) [13] is formed using existing metallic components, with extra cables added where necessary. Typically a 4-wire system is used with a solid grounded neutral point [2] [14]. This grounding method enables good selectivity of low impedance faults with ensures the highest level of selectivity for short-circuit ground faults across metallic sections of the aircraft.

The CRN or ESN system is internal to the aircraft, whereas a copper mesh to protect the aircraft against lightning strike is on the external side of the skin of the aircraft [15].

\section{B. Electrical fault detection criteria for the MEA}

Traditionally, the electrical fault detection criteria for aircraft are focussed on fast fault detection to prevent the propagation of the fault effects throughout the network and ensure the survival of the electrical system (and ultimately the aircraft)[16]. However, ground faults through CFRP may induce low magnitude fault currents by comparison from which the risk of thermal damage to the CFRP panels will likely exceed the risk to the electrical system components and will hence necessitate the specification of new protection system requirements.

According to [17], electrical fault detection and response criteria can be categorised into five areas: speed to ensure the ability to operate within an appropriate time frame; selectivity such that only the protection devices required to isolate the fault operate; sensitivity to ensure that less severe faults are detected; stability such that the protection system does not respond to non-fault conditions or faults outside of a designated zone; reliability such that the protection equipment will operate when required.

Ultimately an electrical fault detection and resulting protection system must be designed with the consideration of all five fault detection and response criteria. However, for this study, the focus is primarily on determining the required speed to detect and respond to an electrical fault to prevent damage to the CFRP material and the required sensitivity to detect the potentially low-current faults. The selectivity and stability of the electrical fault detection criteria can be considered once candidate electrical fault detection and protection solutions have been identified. Similarly, reliability aspects of the fault detection and protection system, and the selection of back up protection solutions, will be heavily influenced by the choice of candidate primary electrical fault detection methods, protection solutions and fault interruption devices.

In order to effectively determine speed and sensitivity fault detection criteria for CFRP-ground fault protection systems, a comprehensive understanding of CFRP electrical and thermal characteristics and behaviour under fault current conduction conditions is first required.

\section{Identification of Research Hypothesis}

There is very limited published literature investigating the fault response of an aircraft electrical power system when CFRP forms the route to ground for short circuit to earth electrical faults. Evans [18] reported significant Joule heating, resulting in fire, with initial power levels of around $100 \mathrm{~W}$, when current was injected through a small area of Hexcel ${ }^{\circledR}$ 8552/IM7 unidirectional (UD) CFRP material. However, the full electrical response of the CFRP was not presented, results were not extrapolated up to full scale power levels, the layup of the CFRP samples used and exact contact surface area of the fault were not provided. Hence it is not possible to extract electrical fault detection requirements or make informed decisions relating to protection system development based on this study. Piche et al. [19] have investigated fault response for quasi-isotropic (QI) UD CFRP, focusing on derivation and validation of an electrical model for the variation of the resistance of QI CFRP as it degrades due to Joule heating. However, no consideration of temperature threshold that electrical protection must detect and appropriately react to a fault through CFRP is given, and no analysis of the time taken to reach this threshold temperature is presented. Additionally, the range of possible impedances added to the fault path is not fully explored and the subsequent impact on selectivity and sensitivity of protection requirements not considered. Rivenc et al [21][22] have studied the fault response of QI CFRP, with a focus on the thermal degradation of CFRP due to Joule heating. Whilst [21][22] indicate that Joule heating from fault current is 
This is a pre-print of TTE-Reg-2017-12-0232, accepted by the IEEE Trans. on Transportation Electrification on $19^{\text {th }}$ April 2018 and as such is subject to IEEE copyright.

sufficient to cause degradation to CFRP, the results are not applied to the development of fault detection methods for MEA electrical power systems on composite aircraft.

The first step to developing an appropriate electrical protection system is to capture the electrical fault detection requirement of speed for ground faults through CFRP, through investigation of the thermal response of CFRP to fault current, to identify the time taken to reach glass transition temperature $\left(T_{g}\right)$. Linked to this there is a need to identify the range of impedances that CFRP may add to the fault path, and the subsequent influence on the sensitivity and selectivity requirements of the electrical protection system.

\section{IMPACT OF CFRP ON FAULT PATH IMPEDANCE}

\section{A. Experimentally Validated Model of CFRP}

The scenario is considered where a solid rail to ground fault occurs through CFRP material, on a DC section of network, due to vibration and chaffing of the insulator. From an electrical perspective, CFRP is a complex material [20]. Whilst QI UD (cross-ply) CFRP or woven CFRP is often used in aerospace applications [23], Uni-directional (UD) $\left[0^{\circ}\right]$ laminates (with all fibres aligned in the same direction in each ply) are an appropriate starting point to develop an understanding and build a foundation for subsequent analysis of QI UD and woven CFRP. Hence, this paper will focus initially on UD $\left[0^{\circ}\right]$ CFRP, more specifically the Hexcel ${ }^{\circledR}$ 8552/IM7 pre-impregnated material system [24]. Full technical detail of the material is presented in Table 1.

Previous research by the authors [7] has experimentally demonstrated the electrical conductivity of this same material to be highly anisotropic: the conductivity $\sigma$ along the fibre $(x)$ direction was found to be $30.3 \mathrm{kS} \cdot \mathrm{m}^{-1}$, compared to the throughthickness $(z)$ direction value of $0.8 \mathrm{~S} \cdot \mathrm{m}^{-1}$ and in-plane transverse $(y)$ direction value of $3.5 \mathrm{~S} \cdot \mathrm{m}^{-1}$. This is demonstrated in Fig. 1, which shows the localised, $x$-direction Joule heating when $4.5 \mathrm{~V}$ is applied to a $10 \mathrm{~mm} \times 10 \mathrm{~mm}$ area in the centre of a UD $\left[0^{\circ}\right]$ CFRP panel $(100 \mathrm{~mm} \times 100 \mathrm{~mm} \times 40$ plies $(\sim 5 \mathrm{~mm})$ ) which is solidly connected to ground on all four edges through a copper foil electrode. The positive electrode was held onto the surface of the CFRP using a clamp, which was insulated electrically and thermally from the CFRP using a $20 \times 20 \times 20 \mathrm{~mm}$ cube of heat proof block. The entry and exit points of the electrical current in the CFRP are indicated in Fig.1.

In order to capture the electrical protection requirements, a lumped impedance electrical model of UD $\left[0^{\circ}\right]$ CFRP has been developed by the authors (described in detail in [7]) and is shown in Fig. 2, where $R_{z}(\Omega)$ and $C_{z}(\mathrm{~F})$ are the resistance and capacitance associated with the $z$ direction, and $R_{x l}$ and $R_{x 2}$ are the resistances associated with the $x$ direction (along fibres). It is known that the capacitance $C_{z}$ is only significant for frequencies in the Gigahertz range or higher [7]. Hence the material can be considered resistive at lower frequencies. There are two resistances in the $x$ direction as it is assumed that all sides of the panel are electrically bonded to ground. This model is of suitable fidelity for use within power systems simulations which require a small time step to capture full system dynamics, without significantly increasing the computational requirements of the simulation.

\section{TABLE 1: TECHNICAL DATA OF THE UD[ $\left[0^{\circ}\right]$ CFRP} INVESTIGATED

\begin{tabular}{|c|c|}
\hline CFRP property & Value \\
\hline Epoxy matrix & $8552 / \mathrm{IM} 7$ \\
\hline Glass transition temperature & $200^{\circ} \mathrm{C}[7]$ \\
\hline Volume fraction carbon fibre & $57.70 \%[7]$ \\
\hline Sample dimensions & $100 \mathrm{~mm} \times 100 \mathrm{~mm} \times 40$ plies $(\sim 5 \mathrm{~mm})$ \\
\hline \multirow[t]{3}{*}{ Conductivity [7] } & $\sigma_{x}=30.3 \mathrm{kSm}^{-1}$ \\
\hline & $\sigma_{\mathrm{y}}=3.5 \mathrm{Sm}^{-1}$ \\
\hline & $\sigma_{\mathrm{z}}=0.8 \mathrm{Sm}^{-1}$ \\
\hline
\end{tabular}

\section{B. Range of Resistance Added to the Fault Path by CFRP}

If a 00 American wire gauge (AWG) cable, which has lost its insulation due to chafing caused by vibration, is pressed against the centre of a panel of CFRP, then the range of impedances added to the fault path by the CFRP can be estimated using the model presented above. In order to achieve this, a number of assumptions are made: that the panel is solidly grounded on all sides [6],[7]; that the panel is $650 \mathrm{~mm}$ wide [25]; that the cable forms a solid, electrical bond against the surface of the CFRP (arcing faults are outside the scope of this paper).

It is also assumed that the panel is square: the method presented can be extended to consider rectangular panels if required for future investigation. From the published literature it is known that a panel may be electrically bonded to ground via metallic bolts [26] rather than a flange/frame [6], or there may be an internal metallic mesh [6]. Hence the electrical resistance model may vary from the baseline model presented, but the assumptions presented in this paper provide a strong, initial platform for the capture of fault detection criteria.

If it is assumed that the top layer of epoxy has been removed by chaffing, reducing $R_{z}$ to an insignificant level, then the total resistance is given by the parallel resistances, $R_{x 1}, R_{x 2}$ (Fig. 2), which represent the two routes to ground taken by the electrical current (Fig.1). The individual resistances are given by,

$$
R_{x 1}=\frac{l_{x 1}}{\sigma_{x} A_{x}} \quad R_{x 2}=\frac{l_{x 2}}{\sigma_{x} A_{x}}
$$

where $R_{x l, x 2}(\Omega)$ is resistance for a specific section of CFRP, $l_{x l, x z}$ $(m)$ is the length from the point of injection to the connection to ground (at the edge of the panel of CFRP),$\sigma_{x}\left(\mathrm{~S}^{-\mathrm{m}^{-1}}\right)$ is the material conductivity specific to the x-direction, and $A_{x}\left(m^{2}\right)$ is the cross-sectional area that the current must flow through to reach ground in a specific direction which is given by,

$$
A_{x}=w_{y} \cdot d_{z}
$$

where $d_{z}(\mathrm{~m})$ is the initial depth that the current will flow through (1.2 plies [7]), and $w_{y}(m)$ is the width of the area that the chaffed cable is in contact with the surface of the CFRP in the $y$-direction.

Hence the total resistance, $R_{c}(\Omega)$ is given by,

$$
R_{c}=\frac{R_{x 1} \times R_{x 2}}{R_{x 1}+R_{x 2}}
$$

If the length of cable in contact with the CFRP is aligned along the fibre direction, and is varied from $2 \mathrm{~mm}$ to $20 \mathrm{~mm}$, 
This is a pre-print of TTE-Reg-2017-12-0232, accepted by the IEEE Trans. on Transportation Electrification on $19^{\text {th }}$ April 2018

and as such is subject to IEEE copyright.

and the percentage of the circumference of the cable in contact with the CFRP panel is varied from $2 \%(0.58 \mathrm{~mm})$ to $20 \%$ $(5.8 \mathrm{~mm})$, then the impedance added by the CFRP to the fault path is as indicated in Fig. 3. For this scenario the resistance is more sensitive to percentage of cable touching (affects crosssectional area, $A)$, than the length of cable touching $(l)$. By inspection of (1), if the orientation of the cable to the fibre direction is rotated $90^{\circ}$, the effective resistance of the CFRP will become more sensitive to the length of cable in contact with the CFRP (affects area, $A$, in (1)), but insensitive to percentage of cable circumference touching the surface area (affects length, $l$, in (1)). The resistance added in this case will range from $\sim 2 \Omega$ to $\sim 16 \Omega$. Hence the impedance that the electrical fault current may have to flow through to reach ground may vary from a few Ohms to several tens of Ohms, indicating sensitivity of CFRP resistance to fibre direction.

\section{EXPERIMENTAL RESPONSE OF CFRP TO FAULT CURRENT}

\section{A. Aims and Objectives}

The experiments aimed to capture the response of a typical aerospace-grade CFRP material to electrical fault current, both electrically and thermally. Firstly, to capture the acceptable time frame for a protection system to detect and respond to an electrical fault before the material starts to degrade due to Joule heating. Hence the protection system must operate before the $T_{g}$ of the polymer matrix is reached, as at this point the matrix may soften considerably resulting in drastic losses of matrixdominated mechanical properties [27]. Secondly experimental results enabled the required sensitivity and selectivity of the protection system to be identified, by combining the electrical model of the material and the systems simulation model (presented in Section V).

\section{B. Methodology}

To inject electrical current through a sample of CFRP, UD $\left[0^{\circ}\right]$ laminates of $\mathrm{Hexcel}^{\circledR}$ 8552/IM7 pre-impregnated sheets

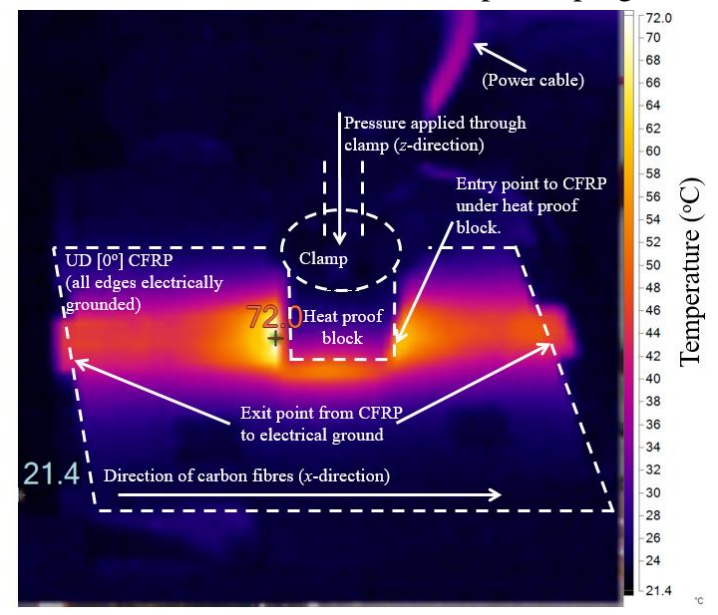

Fig. 1: Thermal image showing the highly anisotropic nature of a UD CFRP laminate subjected to an electrical current.

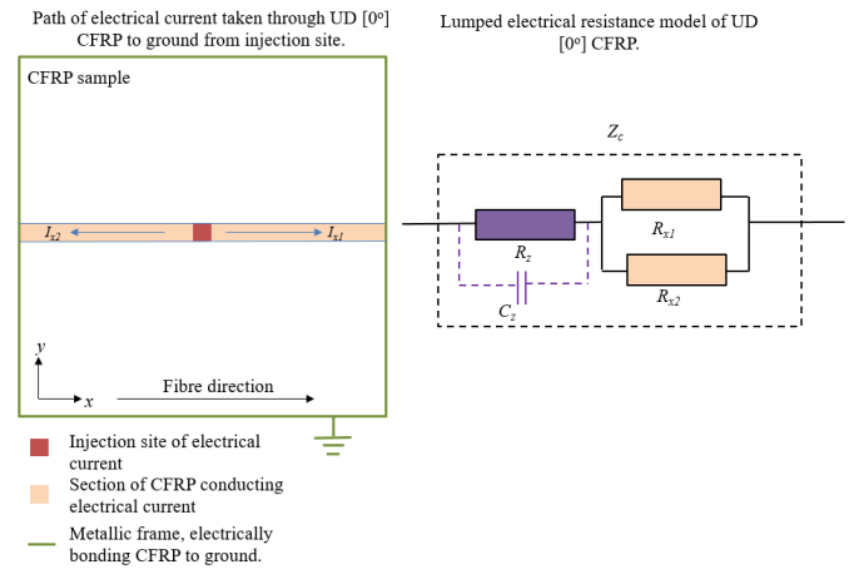

Fig. 2: Indication of the path taken by injected current $\left(I_{x 1}(A), I_{x 2}(A)\right)$ through the uppermost ply of UD $\left[0^{\circ}\right]$ CFRP to reach electrical ground from an injection site (left), carbon fibres aligned to the $x$-axis; Lumped impedance model of UD $\left[0^{\circ}\right] \mathrm{CFRP}, Z_{c}(\Omega)$ (right).

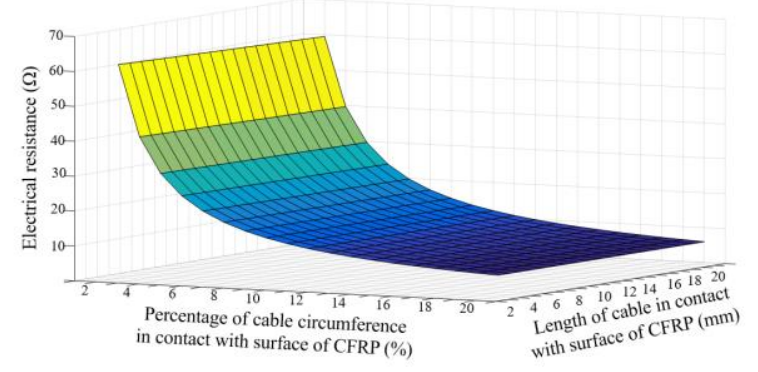

Fig. 3: Variation of impedance with both cable length and percentage of circumference of AWG 00 cable, when cable is laid across surface of CFRP in line with carbon fibres.

were manufactured by stacking 40 plies at a single fibre orientation. After consolidation and cure in an autoclave, the panels were cut into smaller specimens measuring $100 \mathrm{~mm} \times 100 \mathrm{~mm}$ using a diamond-coated circular saw. Each specimen then had three rectangular areas measuring $10 \mathrm{~mm} \times 20 \mathrm{~mm}$ polished on their surfaces, as shown in Fig. 4., using 800 grit sandpaper (10 scrapes along the fibre direction and 2 scrapes perpendicular to it). This mimicked the effect of a cable chafing the surface, reducing the thickness of the outer layer of epoxy. A layer of silver epoxy was applied along one edge of the sample, as indicated in Fig. 4, to minimise contact resistance with the negative electrode (silver epoxy was not applied to the sanded areas on the surface of the material, as this would not be representative of the effect of a cable being pushed against a surface).

Copper foil electrodes were used to apply a DC voltage across the composite specimens as indicated in Fig. 5. A heat proof block was placed between the vice and the electrode (as indicated in Fig. 6) to electrically and thermally insulate the metallic vice from the electrodes and the CFRP. The electrode was arranged at the injection site such that the edge of the 
This is a pre-print of TTE-Reg-2017-12-0232, accepted by the IEEE Trans. on Transportation Electrification on $19^{\text {th }}$ April 2018

and as such is subject to IEEE copyright.

electrode was flush with the edge of the heat proof block. Injected electrical current flowed from the injection site to the exit point, as indicated in Fig. 6.

A range of voltages (3.45-7.21 V) were applied across the CFRP, varying initial power level from $10 \mathrm{~W}$ to $108 \mathrm{~W}$. The time to reach $T_{g}$ was measured for all samples using an infrared thermal camera. Voltage and current measurements were captured using a LabVIEW ${ }^{\mathrm{TM}}$ system, and measured at the locations indicated in Fig. 5. The resistance of the CFRP, resistance added by silver epoxy electrode at the exit point and any contact resistance at the exit and entry points, $R_{c}(\Omega)$ was calculated by,

$$
R_{C}=\frac{V_{C F R P}}{I_{C F R P}}
$$

where $V_{C F R P}(V)$ is the voltage measured across the CFRP (points $A$ and $B$ in fig. 5) and $I_{C F R P}(A)$ is the current measured to be flowing through the CFRP. The resistance added to the system by cables and electrodes, $R_{C C}(\Omega)$, was calculated by,

$$
R_{C C}=\frac{V_{s}-V_{C F R P}}{I_{C F R P}}
$$

where $V_{s}(V)$ is the supply voltage. $\mathrm{R}_{\mathrm{cc}}$ was calculated to be $0.03 \Omega$. Voltage continued to be applied after the $T_{g}\left(200^{\circ} \mathrm{C}\right)$ [24] was reached, in order to observe visual degradation to the CFRP.

\section{Results}

\section{1) Depth of Initial Electrical Current Flow Through CFRP}

The initial resistance of the CFRP was calculated using the voltage and current measurements. Using (1) and (2), the depth of the material that the electrical current will flow through, can be estimated from the initial resistance of the material. From the results obtained (Appendix A), this was found to have a median of 1.2 plies. This further validating the hypothesis presented in [7].

It is well documented in the literature that the carbon fibres in CFRP exhibit a significant amount of waviness, e.g. [28]. Hence the thickness of a ply will vary over a distance and therefore these results indicate strongly that the electrical current flows predominantly through the top layer of CFRP. Furthermore, it indicates that if QI UD is considered, then initial resistance may be similar to that of $\left[0^{\circ}\right] \mathrm{UD}$. Woven CFRP has similar conductivity in both $x$ and $y$ directions, which still dominate over $z$-direction conductivity [29]. Extrapolation of the $\mathrm{UD}\left[0^{\circ}\right]$ model is needed to explore this further, and this is presented in Section V.D.

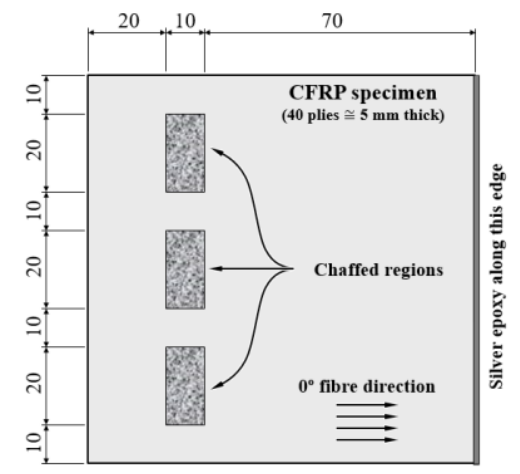

Fig. 4: Geometry of CFRP specimens for electrical current testing (dimensions in millimetres).

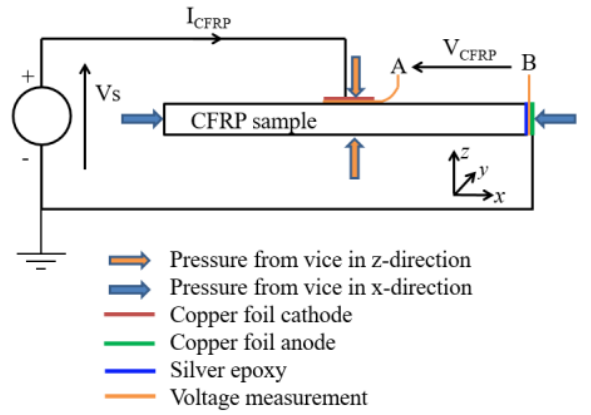

Fig. 5: Diagram of experimental setup, indicating the measurement of the voltage drop across the CFRP (between points A (entry point) and B (exit point)), $V_{C F R P}(V)$ and the measurement of the current conducted, $I_{C F R P}(A)$.

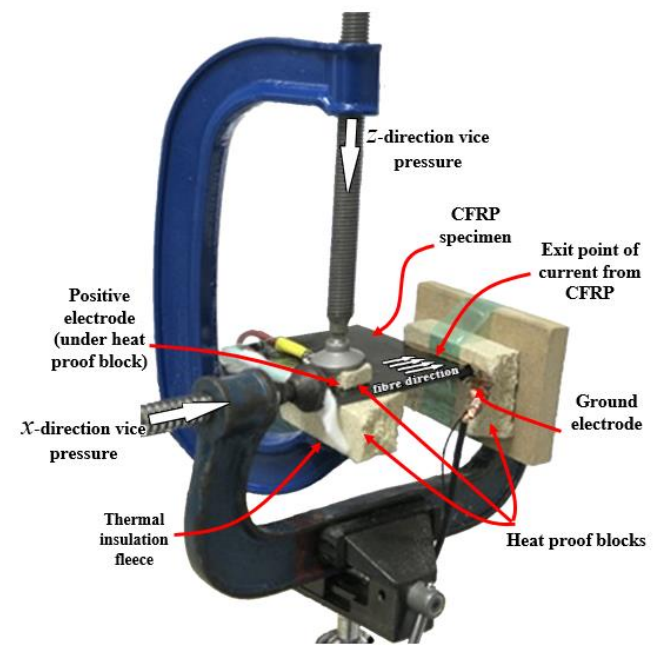

Fig. 6: Photograph of experimental setup (described as a circuit diagram in Fig.5) in the laboratory.

\section{2) Material Response to Electrical Current}

Appendix A summarises results from the experiments to investigate the response of the $\mathrm{UD}\left[0^{\circ}\right]$ CFRP to electrical current. Fig. 7 shows how the electrical resistance of CFRP varies with time and the corresponding variation in dissipation of electrical power in the CFRP when an initial power of 66.27 $\mathrm{W}(7.14 \mathrm{~V})$ was applied to a specimen, demonstrating changes in the electrical properties due to Joule heating. During the initial stage, up to the point where $T_{g}$ is reached, the resistance of the material drops. From the literature, this is known to be due to the semi-conductive nature of carbon fibre [30].

The second stage of degradation identified is from the $T_{g}$ to initial discolouration of the surface of the CFRP. During this phase, the resistance of the material gradually ceases to decrease and starts increasing. This is likely a consequence of the thermal expansion of the matrix, which increases the relative distance between fibres and hence reduces electrical conductivity in the material [33]. The resistance continues to rise into the third stage, as blisters start to form between plies and also between individual fibre bundles. Blisters are clearly seen on the surface of the material. During the fourth stage, the resistance once again starts to decrease, ultimately very rapidly with time, as the resin undergoes thermochemical decomposition increasing direct contact between fibres [19]. 
This is a pre-print of TTE-Reg-2017-12-0232, accepted by the IEEE Trans. on Transportation Electrification on $19^{\text {th }}$ April 2018 and as such is subject to IEEE copyright.

The response of the CFRP observed in each experiment followed a similar shape, but with variations in time to reach the different levels of degradation, to that shown in Fig. 7. The time to reach $T_{g}$ for a range of different levels of electrical power dissipated in CFRP was measured and presented in Fig. 8. The initial power level was calculated from the applied voltage and the initial current conducted through the CFRP. By inspection, these results indicate the relationship between the initial power level and time to reach $T_{g}, t_{T g}(\mathrm{~s})$, to be a nonlinear, decaying power relationship between the initial power dissipated in the CFRP, $P_{i}(\mathrm{~W})$, i.e.,

$$
t_{T g}=1.321 \times 10^{5}\left(P_{i}\right)^{-2.262}+2.95
$$

The relationship in (3) indicates that as the initial power increases, the time to reach the $T_{g}$ tends to $2.95 \mathrm{~s}$ for the samples considered.

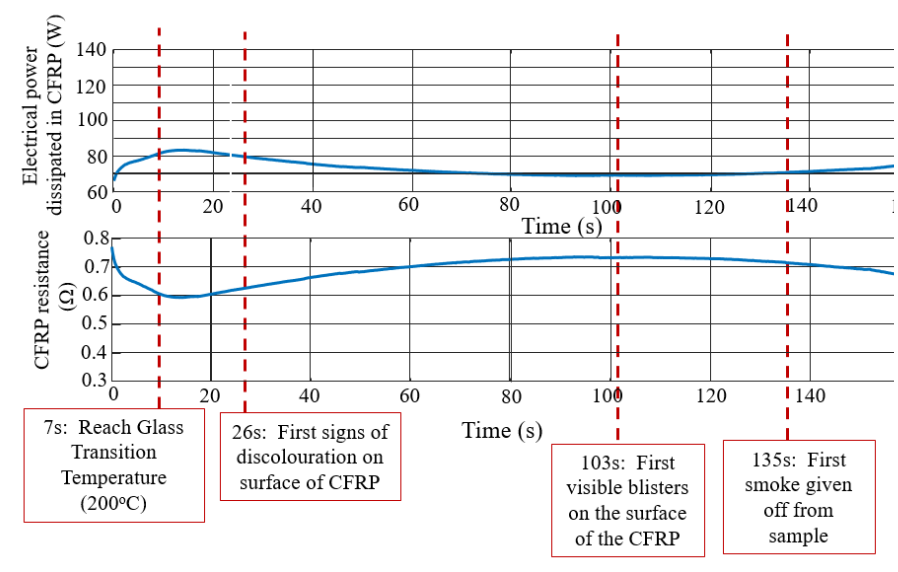

Fig. 7: Response of CFRP to an initial power dissipation of $66.27 \mathrm{~W}$ at $7.14 \mathrm{~V}$.

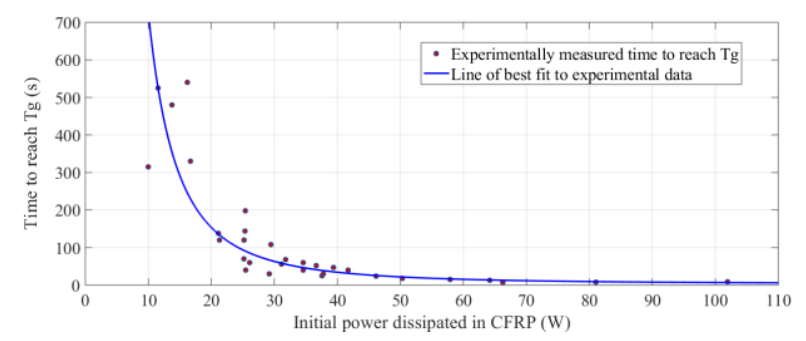

Fig. 8: Time to $T_{g}$ versus initial power level.

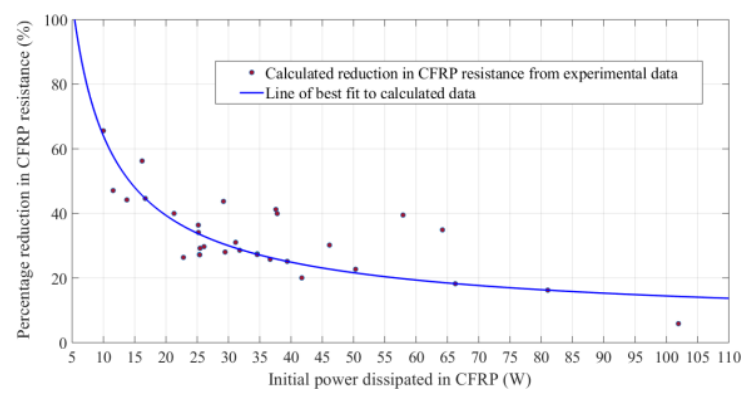

Fig. 9: Percentage change in resistance between initial resistance and resistance at $T_{g}$ versus initial power level.
It is observed in Fig. 7 that the resistance of the CFRP changes in response to Joule heating. The resistance of each sample at $T_{g}$ was measured and the percentage change in resistance calculated using (3). By inspection of Fig. 9 it can be seen that as the initial power level increases, the resistance of the CFRP reduces by $15 \%$ from its initial starting value when $T_{g}$ for the higher power levels considered, tending to $5 \%$ if extrapolated to higher powers. This finding impacts on whether the resistance of the CFRP will drop below a threshold, hence disabling conventional under-voltage and over-current based fault detection methods.

\section{V.INFLUENCE ON FAULT DETECTION REQUIREMENTS}

\section{A. Model of a candidate MEA electrical power system}

For this paper a sub-section of a generic MEA architecture based on [30] and [31] has been modelled to capture the response of a DC rail to ground fault through CFRP. This is shown in Fig. 10. This model has been built using the modular transient modelling tool described in [34], with an ESN impedance taken from [2].

A $236 \mathrm{kVA}$ synchronous generator provides variable frequency voltage to a three phase, $230 \mathrm{~V}$ rms phase AC bus. The generator is modelled as a controlled voltage source behind an appropriate resistance $(6 \mathrm{~m} \Omega)$ and reactance $(151 \mu \mathrm{H})$, with a control loop that regulates the output voltage to maintain the DC link voltage behind the autotransformer rectifier unit (ATRU) at $\pm 270 \mathrm{Vdc}$. A number of resistive loads are connected to the DC link, with an active rectifier interfacing the DC link to an $80 \mathrm{~kW}$ permanent magnet synchronous motor (PMSM) for the environmental conditioning system (ECS).

The feeder between the generator and the ATRU has been modelled using a lumped parameter model [35] and includes three discrete, insulated cables wrapped around a screened and grounded neutral cable, forming a bundle. A neutral wire is used to enclose a current return path for single-phase loads and to maintain steady voltage levels during unbalanced load conditions [2]. The grounded neutral shield conducts stray currents generated by electromagnetic interference [36].

\section{B. Required speed of fault detection}

For the results presented in Section IV, samples of CFRP at a size appropriate for testing in the bench-top laboratory environment at low voltages were used. The range of resistances from the experiments was considerably lower than those calculated and presented in Fig. 3. However, the identified decaying exponential relationship between initial power level and time to reach $T_{g}$, given by (3), enables the extrapolation of results to higher power levels appropriate to MEA architectures.

From the results presented in Fig. 8, it can be concluded that an electrical protection system must detect and appropriately respond to a ground fault through CFRP laminates within a timeframe of the order of seconds to prevent $T_{g}$ being reached, and protect the composite structure from damage. By contrast, a low impedance $(0.01 \Omega)$ positive rail to ground fault will result in a fast, high current transient which requires detection and appropriate response in a time frame of microseconds [15]. Hence the available time frame for the protection system to detect and respond appropriately to a ground fault is unlikely to 
This is a pre-print of TTE-Reg-2017-12-0232, accepted by the IEEE Trans. on Transportation Electrification on 19 ${ }^{\text {th }}$ April 2018 and as such is subject to IEEE copyright.

be a limiting factor on the development of an appropriate electrical fault detection and subsequent protection system.

\section{Impact on selectivity and sensitivity electrical fault detection criteria}

Due to the relatively long time frame available for fault detection and protection system response (compared to low impedance faults) selectivity and sensitivity requirements are likely to be more onerous than detection and operating speed requirements. Reliability and stability requirements are of concern once candidate fault detection and protection solutions are identified. A positive DC rail to ground fault was thrown on the $\pm 270 \mathrm{~V} \mathrm{dc}$ bus using the simulation model of the section of MEA power system shown in Fig. 10. A suite of simulations was then undertaken to investigate the impact of the higher fault impedance on sensitivity and selectivity protection requirements, with the fault resistance varied from $1.5 \Omega$ to $60 \Omega$. In simulation, this gave a variation in initial power dissipated in the CFRP from $46.4 \mathrm{~kW}$ to $1.2 \mathrm{~kW}$ (calculated based on peak, measured fault current).

When a rail to ground fault was applied across the $\pm 270 \mathrm{~V} \mathrm{dc}$ link the voltage dipped. Fig. 11 shows the DC link voltage response when the fault impedance ranged from $1.5 \Omega$ to $4.5 \Omega$. There is to date no standard for the acceptable range of normal operation for the $\pm 270 \mathrm{~V} \mathrm{dc}$ bus. However, based on extrapolation from the existing MIL 704F standard for a $270 \mathrm{~V} \mathrm{dc}$ bus [37], the expected allowable voltage transient envelope is shown by the dashed black line in Fig. 11. By inspection, if the fault impedance is $3.5 \Omega$ or greater, then the resulting DC link transient will remain within the envelope of "normal" operation. Increasing sensitivity of the under voltage protection to detect distant faults with voltage transients of this nature would not be viable, as normal load transients could then lead to mal-operation of the protection system.

Fig. 12 shows the level of fault current measured flowing through the CFRP as the fault resistance was increased from $2.5 \Omega$. to $20 \Omega$. The DC link current under normal operation flowing on the $+270 \mathrm{~V}$ dc bus was measured to be $200 \mathrm{~A}$. By inspection of Fig. 12, the threshold resistance for a $20 \%$ increase in DC link current would be a fault impedance of 6 . $5 \Omega$ or less, and the threshold for $10 \%$ increase is $13.25 \Omega$.

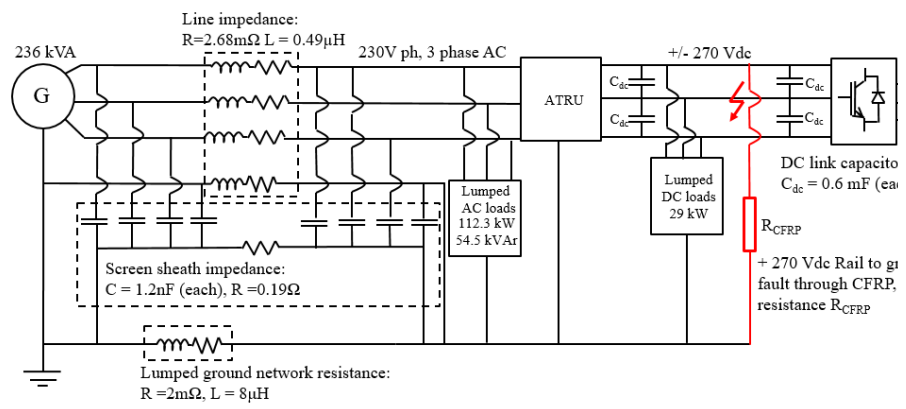

Fig. 10: Example section of MEA architecture for fault response capture.

TABLE 2: GENERATOR AND MOTOR PARAMETERS.

\begin{tabular}{ll}
\hline \hline \multicolumn{1}{c}{ Parameter } & \multicolumn{1}{c}{ Value for PMSM } \\
\hline Stator Resistance & $5 \mathrm{~m} \Omega$ \\
Stator d-axis Inductance & $75 \mu \mathrm{H}$ \\
Stator q-axis Inductance & $77 \mu \mathrm{H}$ \\
Stator 0-seq Inductance & $0.1 \mathrm{mH}$
\end{tabular}

Number of Pole Pairs

Voltage Constant $K e$

Inertia

These results indicate that the resistance added to the fault path by the CFRP is likely to prevent the detection of a fault using conventional over-current or under-voltage based detection methods. Hence it is clear that whilst in some cases the resistance added to the fault path is sufficiently low for existing protection to trip, a secondary fault detection system is required for higher fault resistances due to the CFRP. The results and analysis presented in Figs. 3, 9, 10, 12 and 13, indicate that at higher powers the trend towards a $15 \%$ drop between initial resistance and resistance at $T_{g}$ is unlikely to push the fault resistance to a low enough level before $T_{g}$ is reached for sensitivity and selectivity fault detection requirements to be influenced.1.5

\section{D.Extrapolation of fault detection criteria to QI and woven CFRP laminates.}

Whilst it can be concluded from the results presented in Section IV that resistance of UD $\left[0^{\circ}\right]$ CFRP can be above the threshold level for conventional fault detection (over-current, under-voltage) methods, there is a need to extend this study to QI and woven laminates. From the literature, it is known that the through-thickness conductivity of QI UD laminates is similar to that of UD $\left[0^{\circ}\right]$ laminates [19].

A typical lay-up for a QI UD laminate is [ $45 \% / 90 \%-45 \% \%$ $45 \%$ \% $/ 90 \%$ \% $/ 45 \% \%-45 \% 90 \% 5^{\circ}$ ] [21], where $0^{\circ}$ is aligned to the $x$-axis. If a chaffed 00 AWG cable is pressed against a $650 \mathrm{~mm}$ square of such QI CFRP, such that $10 \%$ of the circumference $(2.91 \mathrm{~mm})$ of the copper is in contact with the surface of the CFRP in the centre of the panel over a distance of $10 \mathrm{~mm}$, then the path that the electrical current will take to reach electrical ground is shown in Fig. 13 It is assumed that the panel is solidly bonded to ground on all sides. From the results presented in Section III, it is predicted that current initially flows through the full depth of the surface ply, and into $20 \%$ of the second ply. Hence the lumped resistance model for QI UD is obtained (Fig. 13) by extrapolating the model presented in Section III, which gives a total initial electrical resistance of,

$$
\begin{aligned}
& R_{C_{-} Q I U D}=\frac{R_{S} R_{p}}{R_{S}+R_{p}} \\
& R_{s}=\frac{R_{S 1} R_{S 2}}{R_{S 1}+R_{S 2}} \\
& R_{p}=\frac{R_{p 1} R_{p 2}}{R_{p 1}+R_{p 2}}
\end{aligned}
$$

where $R_{C \_ \text {IIUD }}(\Omega)$ is the total initial electrical resistance, $R_{S}(\Omega)$ is the initial resistance of the surface ply and $R_{p}(\Omega)$ is the initial resistance contribution of the second ply. $R_{s l}(\Omega), R_{s 2}(\Omega), R_{p 1}$ $(\Omega)$ and $R_{p 2}(\Omega)$ are the individual resistances in the surface and second plies as indicated in Fig. 13.

If QI woven CFRP is considered, with a similar lay-up to the QI UD material with a fibres in the upper most ply aligned at $45^{\circ}$ and the fibres in the second uppermost ply aligned at $90^{\circ}$, then from the literature the material is predicted to have similar conductivities in the $x$ and $y$ directions, with conductivity in the $z$ direction very low in comparison [29]. Fig. 14 indicates the predicted path that the fault current will take through a QI woven CFRP. As for QI UD, it is predicted that the depth of 
This is a pre-print of TTE-Reg-2017-12-0232, accepted by the IEEE Trans. on Transportation Electrification on $19^{\text {th }}$ April 2018 and as such is subject to IEEE copyright.

current flow will include all of the surface ply and circa $20 \%$ of the second ply. Hence, the total resistance is extrapolated to be,

$$
\begin{aligned}
& R_{C_{-} Q I W}=\frac{R_{S} R_{p}}{R_{S}+R_{p}} \\
& R_{S}=\frac{R_{S 1} R_{S 2} R_{S 3} R_{S 4}}{R_{S 1} R_{S 2} R_{S 3}+R_{S 2} R_{S 3} R_{S 4}+R_{S 1} R_{S 2} R_{S 4}+R_{S 1} R_{S 3} R_{S 4}} \\
& R_{p}=\frac{R_{p 1} R_{p 2} R_{p 3} R_{p 4}}{R_{p 1} R_{p 2} R_{p 3}+R_{p 2} R_{p 3} R_{p 4}+R_{p 1} R_{p 2} R_{p 4}+R_{p 1} R_{p 3} R_{p 4}}
\end{aligned}
$$

where $R_{C \_Q I W}(\Omega)$ is the total initial electrical resistance, $R_{s}(\Omega)$ is the initial resistance in the upper most ply and $R_{p}(\Omega)$ is the initial resistance contributed by the second ply. $R_{s 1}(\Omega), R_{s 2}(\Omega)$, $R_{s 3}(\Omega), R_{s 4}(\Omega), R_{p 1}(\Omega), R_{p 2}(\Omega), R_{p 3}(\Omega)$ and $R_{p 4}(\Omega)$ are the individual resistances in the upper and second plies as indicated in Fig. 13.

Using (6) - (11), the initial resistance was calculated and compared for a set of different lay-ups of CFRP, with the presented in Table 3. For each lay-up two scenarios were considered: firstly $10 \%(2.91 \mathrm{~mm})$ of the circumference of a a distance of $5 \mathrm{~mm}$, and secondly $5 \%(1.455 \mathrm{~mm})$ of the cable circumference was in contact with the surface over a distance of $20 \mathrm{~mm}$. In both cases the cable was orientated along the $x$ axis. A woven layup with the first two plies orientated at $\left[0^{\circ}, 90^{\circ}\right]$ or $\left[90^{\circ}, 0^{\circ}\right]$ will give the same result as woven $\left[0^{\circ}\right]$.

By inspection of Table 3 it is clear that the CFRP resistance is sensitive to both the orientation and area of the entry point on the surface of the CFRP, and the lay-up of the CFRP. It is not explored in Table 3, but CFRP panel dimensions and the method of electrically bonding the panel to ground will also impact on the path through the CFRP of electrical current, influencing electrical resistance added by the CFRP. The example results in Table 3 indicate that in certain cases the electrical fault resistance is below the thresholds identified in Figs. 11 and 12, indicating a need for high and low resistance fault detection. However, considering the sensitivities outlined

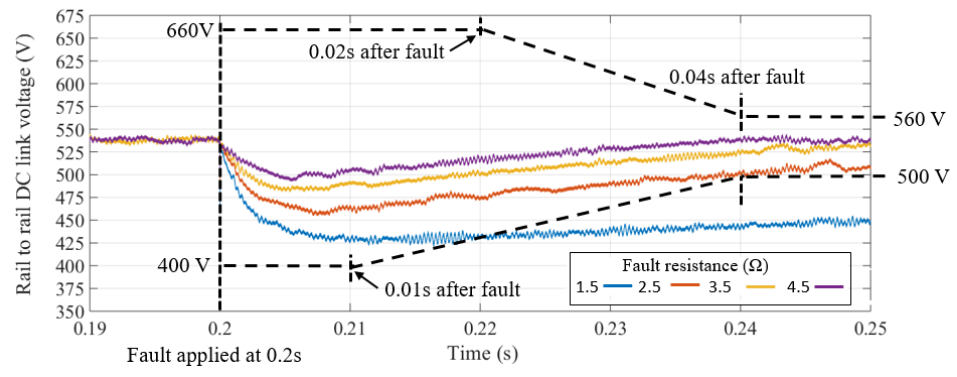

Fig. 11: Rail to rail $540 \mathrm{~V}$ DC link voltage transient for a fault impedance ranging from $1.5 \Omega$ to $4.5 \Omega$.

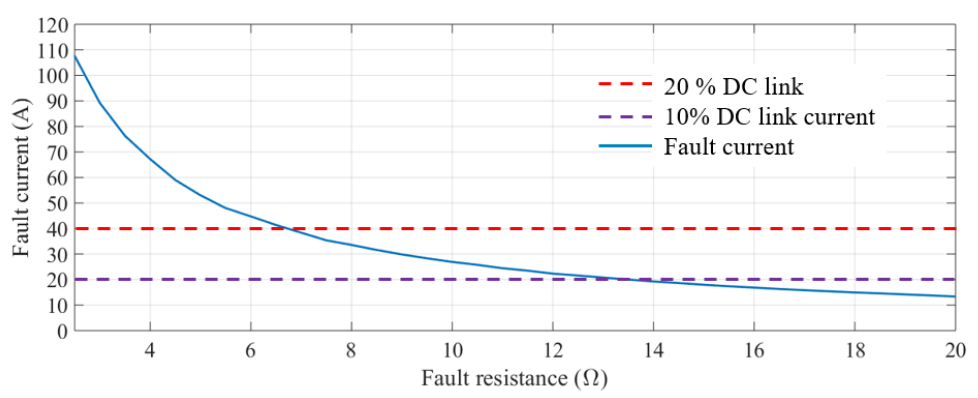

Fig. 12: Variation in fault current as fault resistance rises from $0.5 \Omega$ to $20 \Omega$.

above, there may be opportunity to design lay-up and integration of CFRP with the current return network to control fault resistance to fit within defined threshold values for fault detection methods.

The thermal response for different layups, and how this affects fault detection requirements (in particular speed), requires future investigation. The thermal resistance of a block of material can be given by,

$$
R_{t h}=\frac{d}{\lambda A}
$$

where $d(\mathrm{~m})$ is the distance along which heat flows, $A\left(\mathrm{~m}^{2}\right)$ is the cross-sectional area that it flows through, and $\lambda\left(\mathrm{W} /\left(\mathrm{m} \cdot{ }^{\circ} \mathrm{C}\right)\right)$ is the thermal conductivity. The thermal conductivity of UD CFRP increases as temperature increases [33]. Hence as the power dissipated in the material increases, the thermal resistance will increase, but at a slower rate than the power increase. Therefore the time taken to reach $T_{g}$ may decrease at higher powers, affecting the extrapolation of Fig. 8 to higher powers and for different layups of CFRP.

\section{V.CONCLUSIONS}

The results and discussion have firstly identified a second set of fault detection criteria applicable to the integration of the current return network with the composite structure of an aircraft, with the primary role of the protection system swapping from protection of the electrical power system to protection of the aircraft structure. The results presented in this paper provide a platform from which to set selectivity and sensitivity criteria for detecting electrical faults to ground through CFRP. Whilst this paper has focussed on the MEA, the expected move towards hybrid electric aircraft (HEA), will necessitate the extension of the models presented to the high voltage and power levels proposed for HEA as well as the accommodation of new architectures. The higher voltages and safety criticality of the electric propulsion loads proposed for HEA indicate a strong need for reliable and fast detection methods for arc faults, as well as for solid short circuit faults.

Secondly results indicate that detection criteria are driven by the method used to electrically bond CFRP to the current return network, the CFRP layup and the orientation of the CFRP fibres to the surface of the CFRP. For example, if an electrically conductive metallic sheet that forms part of the current return path is inserted in the composite structure [6], if a panel is electrically bonded to ground though bolts [19], or if it is grounded by a flange along one side of the material [6] then the path to ground taken through the CFRP may result in a much lower, or higher resistance. Localised heating at entry and exit points may also be affected (with consideration of (12)) and the speed with which an electrical fault must be detected.

Combined with sensitivities to lay-up, a future option may be to design the system such that CFRP resistance can be kept within pre-defined thresholds as far as possible.

Linked to this, there is a strong need in future research to consider the impact of different grounding systems, including the location and rating of connection points to electrical ground 
This is a pre-print of TTE-Reg-2017-12-0232, accepted by the IEEE Trans. on Transportation Electrification on $19^{\text {th }}$ April 2018 and as such is subject to IEEE copyright.

on fault response. This must include consideration of relevant certification standards [40], ensuring segregation requirements concerning sharing common ground and the use of double

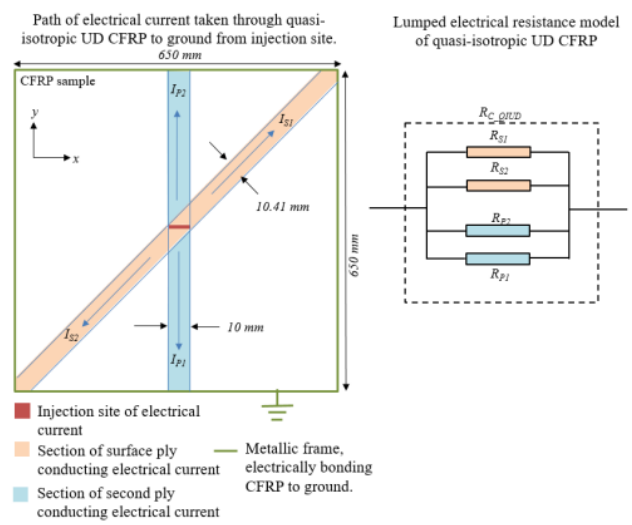

Fig. 13: Predicted path of electrical current through a QI UD CFRP, where the upper ply is aligned at $45^{\circ}$ to the $\mathrm{x}$-axis, the second uppermost ply is aligned at $90^{\circ}$ to the $\mathrm{x}$-axis (right); The predicted lumped electrical model of the initial resistance added to the fault path by the QI UD CFRP (left).

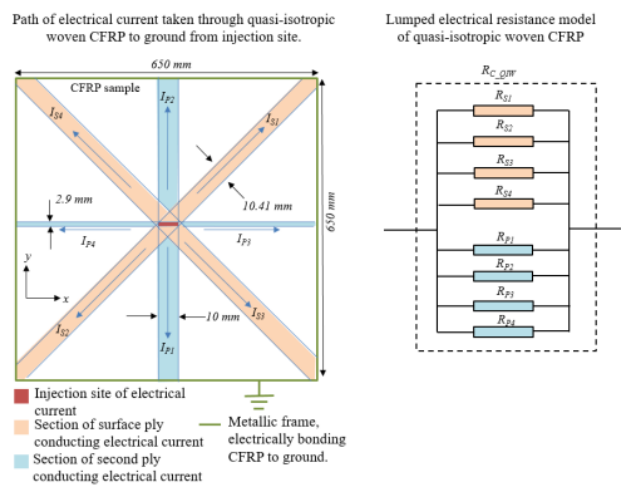

Fig. 14: Predicted path of electrical current through a QI woven CFRP, where the upper ply is aligned at $45^{\circ}$ to the $x$-axis, the second uppermost ply is aligned at $90^{\circ}$ to the $x$-axis (right); The predicted lumped electrical model of the initial resistance added to the fault path by the QI woven CFRP (left).

electrical lines are observed. Secondly, the possibility of alternative grounding topologies which may result in fault criteria being less sensitive to fault resistance (e.g. isolated terra or high resistance grounded systems), where a rail to ground fault will result in a change to the rail to ground voltage level [38], merit attention. Methods to detect faults in such systems in land and marine applications include the use of frequency analysis [39]. Further study is required to investigate their applicability to aerospace applications, supporting the design of appropriate grounding and protection systems for the integration of electrical power systems with composite aerostructures, for both MEA and HEA.

\section{REFERENCES}

[1] B. Sarlioglu and C.T. Morris, "More electric aircraft: Review, challenges and opportunities for commercial transport aircraft", IEEE Trans. Transportation Electrification, vol. 1, no. 1, pp 54 -64, 2015.

[2] M. Teroede, H. Wattar and D. Schulz, "Phase balancing for aircraft electrical distribution systems", IEEE Trans. on Aerospace and Electronic Systems, vol. 51, no. 3, pp.1781-1792, 2015.
[3] International Civil Aviation Organization, "Forecasts of scheduled passenger and freight traffic" [Online], http://www.icao.int/sustainability/pages/eap_fp_forecastmed.aspx

[4] T. Schröter and Schulz, "The electrical aircraft network - benefits and drawbacks of modifications", IEEE Trans. on Aerospace and Electronic Systems, Vol. 49, No. 1, pp. 189-200, 2013.

\section{TABLE 3: INITIAL RESISTANCE ADDED TO FAULT PATH BY} CFRP FOR DIFFERENT LAYUPS.

\begin{tabular}{lcc}
\hline \multicolumn{1}{c}{ Lay-up } & \multicolumn{2}{c}{ Total Resistance $(\Omega)$} \\
\hline & Cable contact area: & Cable contact area: \\
& $10 \times 2.91 \mathrm{~mm}$ & $5 \times 1.075 \mathrm{~mm}$ \\
\hline $\mathrm{UD}\left[0^{\circ}\right]$ & 12.89 & 25.78 \\
$\mathrm{UD}\left[0^{\circ}, 90^{\circ}, ..\right]$ & 8.73 & 17.46 \\
$\mathrm{UD}\left[90^{\circ}, 0^{\circ}, ..\right]$ & 4.05 & 8.1 \\
$\mathrm{UD}\left[45^{\circ}, 90^{\circ}, ..\right]$ & 4.56 & 9.12 \\
$\mathrm{UD}\left[90^{\circ}, 45^{\circ}, ..\right]$ & 3.73 & 4.76 \\
$\mathrm{UD}\left[0^{\circ}, 45^{\circ}, ..\right]$ & 9.79 & 19.58 \\
Woven $\left[0^{\circ}\right]$ & 2.77 & 5.54 \\
Woven $\left[45^{\circ}, 90^{\circ}, ..\right]$ & 2.47 & 4.9 \\
Woven $\left[90^{\circ}, 45^{\circ}, ..\right]$ & 2.69 & 5.38 \\
\hline \hline
\end{tabular}

\section{APPENDIX A}

TABLE 4: SUMMARY OF RESULTS FROM EXPERIMENTS DESCRIBED IN SECTION IV

\begin{tabular}{|c|c|c|c|c|}
\hline $\begin{array}{l}\text { Voltage } \\
\text { applied } \\
\text { across } \\
\text { CFRP }(V)\end{array}$ & $\begin{array}{l}\text { Initial } \\
\text { resistance } \\
\text { of CFRP } \\
(\Omega)\end{array}$ & $\begin{array}{l}\text { Initial } \\
\text { power } \\
\text { dissipated } \\
\text { in CFRP } \\
(W)\end{array}$ & $\begin{array}{l}\text { Resistance } \\
\text { of CFRP at } \\
T_{g}(\Omega)\end{array}$ & $\begin{array}{l}\text { Power } \\
\text { dissipated } \\
\text { in CFRP at } \\
T_{g}(W)\end{array}$ \\
\hline 3.45 & 0.56 & 21.12 & 138 & 0.40 \\
\hline 3.89 & 1.10 & 13.75 & 480 & 0.61 \\
\hline 4.01 & 1.39 & 11.55 & 525 & 0.74 \\
\hline 4.08 & 1.66 & 9.99 & 315 & 0.57 \\
\hline 4.14 & 0.41 & 41.72 & 40 & 0.33 \\
\hline 4.21 & 0.48 & 36.65 & 52 & 0.36 \\
\hline 4.23 & 0.56 & 31.79 & 68 & 0.40 \\
\hline 4.29 & 0.59 & 31.14 & 56 & 0.41 \\
\hline 4.38 & 0.76 & 25.35 & 144 & 0.55 \\
\hline 4.43 & 0.67 & 29.46 & 108 & 0.48 \\
\hline 4.44 & 1.22 & 16.19 & 540 & 0.53 \\
\hline 4.58 & 0.82 & 25.40 & 198 & 0.60 \\
\hline 4.59 & 1.26 & 16.69 & 330 & 0.70 \\
\hline 4.82 & 0.67 & 34.59 & 60 & 0.49 \\
\hline 4.90 & 0.92 & 26.08 & 60 & 0.65 \\
\hline 4.91 & 0.95 & 25.46 & 40 & 0.67 \\
\hline 4.92 & 0.96 & 25.20 & 120 & 0.63 \\
\hline 4.94 & 0.97 & 25.17 & 70 & 0.62 \\
\hline 4.95 & 1.15 & 21.30 & 120 & 0.69 \\
\hline 4.95 & 0.84 & 29.20 & 30 & 0.47 \\
\hline 5.22 & 0.69 & 39.39 & 47 & 0.52 \\
\hline 5.23 & 0.73 & 37.57 & 25 & 0.43 \\
\hline 5.24 & 0.73 & 37.78 & 30 & 0.44 \\
\hline 5.29 & 0.81 & 34.59 & 40 & 0.59 \\
\hline 5.59 & 0.62 & 50.33 & 18 & 0.48 \\
\hline 5.85 & 0.34 & 101.94 & 9 & 0.32 \\
\hline 6.36 & 0.88 & 46.15 & 24 & 0.61 \\
\hline 7.09 & 0.62 & 81.05 & 8 & 0.52 \\
\hline 7.14 & 0.77 & 66.27 & 7 & 0.63 \\
\hline 7.21 & 0.81 & 64.21 & 13 & 0.53 \\
\hline
\end{tabular}

[5] J. Brombach and D. Schulz, "Electric power supply system for an aircraft, aircraft and airport power supply system", Patent US 2014/0132062 A1, May $15^{\text {th }} 2014$.

[6] J. Dalton, P. Broughton, R. Peace, A. Skinner and R.C. Kennea, "Rigid Raft”, U.S. Patent 0160460 A1, Jun. 27, 2013. 
10

This is a pre-print of TTE-Reg-2017-12-0232, accepted by the IEEE Trans. on Transportation Electrification on $19^{\text {th }}$ April 2018

and as such is subject to IEEE copyright.

[7] C.E. Jones et al., "Electrical model of carbon fibre reinforced polymers for the development of electrical power protection systems for moreelectric aircraft", $18^{\text {th }}$ European Conference on Power Electronics and Applications, 2016.

[8] Y. Wang; "Multiphysics analysis of lightning strike damage in laminated carbon/glass fiber reinforced polymer matrix composite materials: A review of problem formulation and computational modeling", Composites: Part A, vol. 101, pp. 543-553, 2017.

[9] P. Feraboli and M. Miller, "Damage resistance and tolerance of carbon/epoxy composite coupons subjected to simulated lighting strike", Composites Part A: Applied Science and Manufacturing, vol. 40, no. 67, pp.954 - 967, July 2009.

[10] "Aircraft Electrical Systems", Federal Aviation Administration Advisory Circular 43.13-1B, Chapter 11 "Acceptable methods, techniques, and practices - Aircraft inspection and repair", 1998.

[11] G.G. Gutierrez, D. M. Romero and M. R. Cabello, "On the design of aircraft electrical structure networks", IEEE trans. on Electromagnetic Compatibility, vol. 58, No. 2, pp. 401 - 408, 2016.

[12] S. M. Braden, M. J. Doherty and S.M. Scott, "Current Return Network", U.S. Patent 8031458 B2, Oct. 4, 2011.

[13] C. Lochot and D. Slomianowski, "A350 XWB Electrical Structure Network”, Airbus Technical Magazine, No. 53, pp. 20-25, 2014.

[14] C. Baumann, L. Prisse, J. Richer and D. Alejo, "Electrical power supply system for an aircraft", U.S. Patent 0025604 A1, Feb. 2012.

[15] H. Kawakami and F. Feraboli, "Lightning strike damage resistance and tolerance of scarf-repaired mesh-protected carbon fiber composites", Composites Part A: Applied Science and Manufacturing, vol. 42, no. 9, pp. 1247 - 1262, Sept. 2011.

[16] S.D.A. Fletcher et al., "Determination of protection system requirements for DC UAV electrical power networks for enhanced capability and survivability", IET Electrical Systems in Transportation, vol. 1, issue 4, pp. $137-147,2011$.

[17] Network Protection and Automation Guide, Alstom Grid, 2011.

[18] R.W. Evans, "Test report - Fault current through graphite filament reinforced plastic", NASA Contractor Report 4774, April 1997.

[19] A. Piche, D. Andissac and I. Revel., "Dynamic electrical behaviour of a composite material during a short circuit", $10^{\text {th }}$ International Symposium on Electromagnetic Compatibility (EMC Europe), 2011.

[20] Z. Xia, T. Okabe, J.B. Park, W.A. Curtin and N. Takeda, "Quantitative damage detection in CFRP composites: coupled mechanical and electrical models", Composites Science and Technology, Vol. 63, No. 10, pp 1411-1422, 2003, DOI: 10.1016/S0266-3538(03)00083-6.

[21] J. Rivenc et al, "A multiphysic approach to predict the degradation of a composite material due to current injection", $17^{\text {th }}$ European Conference on Composite Materials, 2016.

[22] J. Rivenc et al, "Methodology for predicting degradation shape and depth of a CFRP during short-circuit current injection", More Electric Aircraft Conference, 2015.

[23] FAA Aviation Maintenance Technician Handbook: Airframe, Chapter 7: Advanced Composite Materials, FAA, 2012.

[24] "HexPly 8552 Epoxy Matrix", [Online], Available: www.hexcel.com/Resources/DataSheets/Prepreg

[25] R. Perraud et al., "Metallic strip technologies for validation of ESN technologies", Smart Intelligent Aircraft Structures, DOI: 10.1007/9783-319-22413-8_45, 2016

[26] R. Perraud et al, "Installation of metallic strip on CFRP frames: assessment of IS13 mechanical and electrical performance", Smart Intelligent Aircraft Structures, DOI: 10.1007/978-3-319-22413-8_53, 2016

[27] P.K. Mallick, Fiber-reinforced composites, NY, US, Marcel Dekker Inc., vol. 280, pp.40-41, 1988.

[28] E.H. Mansfield and D. Purslow, "The influence of fibre waviness on the moduli of unidirectional fibre reinforced composites", Aeronautical Research Council, C.P. no. 1339, 1974.

[29] F. D. Senghor, G. Wasselynck and H.K. Bui, "Electrical conductivity tensor modelling of stratified woven-fabric carbon fiber reinforced polymer composite materials", IEEE Trans. on Magnetics, vol. 53, no. 6, 2017.

[30] P. Wheeler, "Technology for the more and all electric aircraft of the future", IEEE International Conference on Automatica, 2016.

[31] G.A. Whyatt and L.A. Chick, "Electrical generation for more electric aircraft using sold oxide fuel cells", Pacific Northwest National Laboratory, U.S. Department of Energy, 2012.
[32] K. Takahasi and H.T. Hahn, "Investigation of temperature dependency of electrical resistance changes for structural management of graphite/polymer composite", Journal of Composite Materials, 45(25), pages $2603-2611,2011$.

[33] N.L. Hancox, "Thermal effects on polymer matrix composites: Part 2. Thermal degradation" Materials and Design, 19, pp. 93-97, 1998.

[34] M. Sztykiel et al., "Modular and Reconfigurable Transient Modeling and Simulation Design Support Tool for MEE/MEA Power Systems", SAE AeroTech Conference, 2016, DOI: 10.4271/2016-01-2031.

[35] L. R. Lewis et al., "Modeling, analysis and design of distributed power systems," 20th Annual IEEE Power Electronics Specialists Conference, vol. 1, pp. 152-159, 1989.

[36] J.J. White, "Power feeder shielding for electromagnetic protection," U.S. Patent 9036323 B1, August 18, 2015.

[37] “Aircraft Electric Power Characteristics", MIL-704F, US Department of Defense, 2004.

[38] T. Baldwin et al., "Fault locating in ungrounded and high-resistance grounded systems", IEEE Trans. on Industry Applications, vol. 37, no. 4, pp. $1152-1159,2001$.

[39] Y. Pan, M. Steurer and T. L. Baldwin, "Ground fault location testing of a noise-pattern-based approach on an ungrounded dc system," IEEE Trans. on Industry Applications, vol. 47, no. 2, pp. 996-1002, March 2011.

[40] -, "Certification Specifications and Acceptable Means of Compliance for Large Aeroplanes CS-25", European Aviation Safety Agency, Amendment 19, 2017. 